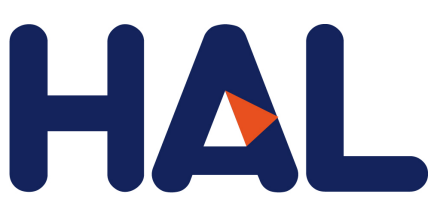

archives-ouvertes

\title{
An application of Hybrid Bayesian Network (HBN) in Hybrid Electric Vehicle (HEV) manufacturing
}

\section{Muneer Mujahed Lyati}

To cite this version:

Lyati Muneer Mujahed, An application of Hybrid Bayesian Network (HBN) in Hybrid Electric Vehicle (HEV) manufacturing 2021

\section{Working paper on Artifical Intelligence}

\section{HALId:hal-02102982}

Preprint submitted on 7 Jan 2021

HAL is a multi-disciplinary open access archive for the deposit and dissemination of scientific research documents, whether they are published or not. The documents may come from teaching and research institutions in France or abroad, or from public or private research centers.
L'archive ouverte pluridisciplinaire HAL, est destinée au dépôt et à la diffusion de documents scientifiques de niveau recherche, publiés ou non, émanant des établissements d'enseignement et de recherche français ou étrangers, des laboratoires publics ou privés. 


\title{
An application of Hybrid Bayesian Network (HBN) in Hybrid Electric Vehicle (HEV) manufacturing
}

\section{Muneer Mujahed Lyati}

January, 2021

\begin{abstract}
:
A network is a hybrid Bayesian network if it has both discrete and continuous variables. In this research, we discuss how the hybrid Bayesian network can utilized to further understand the network from subsidies, manufacturing to the environmental quality in the context of Hybrid electric vehicles.
\end{abstract}

Keywords: HBN, HEV, manufacturing, artificial intelligence.

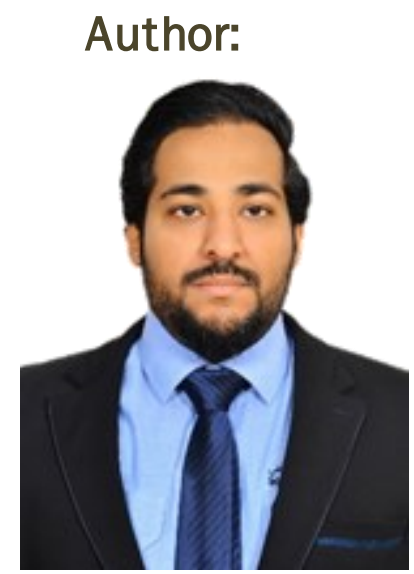

Muneer Mujahed Lyati is a Graduate from College of Technology in mechanical engineering as a bachelor of science in mechanical engineering with major Engines and Vehicles. His research mainly focuses on automotive factors, hybrid cars, electrical cars, engines, and artificial intelligence https://muneerlyati.com/ 


\section{Background}

Global demand for electric vehicles in 2019 was USD 160.34 trillion and is estimated to hit USD 793.24 trillion by 2027 for a CAGR of 22.2 per cent. The demand is largely driven by increased government policies and programs to promote the adoption of electric vehicles (EVs). Increasing investment in R\&D for the development of advanced technologies is also fueling the growth of the industry. Compared to conventional vehicles, emission levels are much lower in electric vehicles, which has led the government to encourage the production of EVs all over the world. [1] [2] [3].

[4], [5] [6], [6] [5] [7]

Asia Pacific had the biggest market share in the electric vehicles market in 2019. The growing demand for electricity supplies in countries like China, Malaysia, India and Indonesia is due to a growing urban population. Moreover, government action to reduce pollution has led to the increasing adoption of EVs. Given the growing environmental awareness and increasing investment in new technology by key manufacturers, North America is expected to report significant growth over the forecast period [1] [8].

$\mathrm{HEV}$ can also help producers: by increasing the worldwide $\mathrm{CO} 2$ emission targets, HEV sales can reduce the overall CO2 output of a manufacturer's fleet and help to prevent the related fines. In fact, in Europe, the report finds that several automakers will not meet the emission goals and will either have to buy credits from other manufacturers or face heavy fines. The advantages of $\mathrm{CO} 2$ reduction from HEVs are nowhere near those of BEV and PHEV drivetrains. The technology is however maturer and can thus serve as a short-term stopover to achieve these objectives.

\section{Bayesian networks}


Bayesian networks are a type of probabilistic graphic model which uses the Bayesian inference to calculate probability. The Bayesian networks have the objective of modeling conditional dependency and thus cause, by representing conditional dependence in a directed graph by edges. Through these relationships, the random variables of the graph can be efficiently deduced using factors.

\section{Hybrid Bayesian network and Hybrid electric vehicle}

A network is called a hybrid Bayesian network if it has both discrete and continuous variables. We need to specify two new types of distribution in order to specify a hybrid network: the conditions for a constant variable given to discerning or continuous parents, and the conditional distribution for a discrete variable given to continuous parents [9] [10]

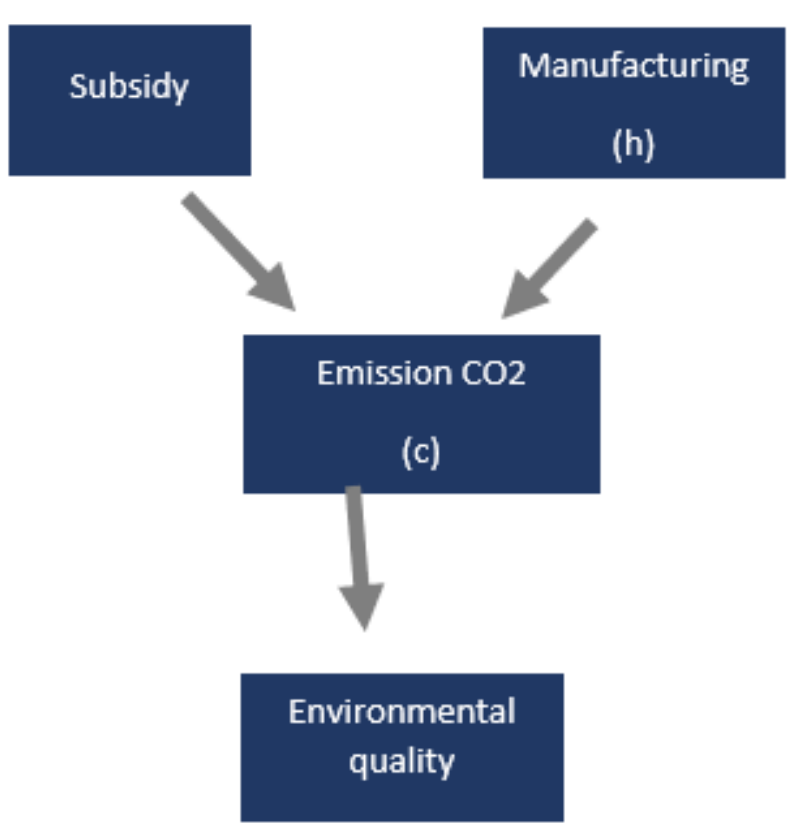

Figure 1: A network with discrete variables (Subsidy and environmental quality) and continuous variables (manufacturing and emission). 
The linear Gaussian distribution, in which the child has a Gaussian distribution whose mean $\mu$ varies linearly with the value of the parent and whose standard deviation $\sigma$ is fixed, is the most fundamental choice in our case. Two distributions are necessary, one for subsidies and one for -subsidies.

$$
\begin{aligned}
P(c \mid h, \text { subsidy }) & =N\left(a_{t} h+b_{t}, \sigma_{t}^{2}\right)(c)=\frac{1}{\sigma_{t} \sqrt{2 \pi}} e^{-\frac{1}{2}\left(\frac{c-\left(a_{t} h+b_{t}\right)}{\sigma_{t}}\right)^{2}} \\
P(c \mid h, \neg \text { subsidy }) & =N\left(a_{f} h+b_{f}, \sigma_{f}^{2}\right)(c)=\frac{1}{\sigma_{f} \sqrt{2 \pi}} e^{-\frac{1}{2}\left(\frac{c-\left(a_{f} h+b_{f}\right)}{\sigma_{f}}\right)^{2}} .
\end{aligned}
$$

Figure 2 demonstrates the distribution of probability over emissions as a function of the size of production, with true and false subsidies, respectively. The last panel in Figure 2 shows the $\mathrm{P}$ (Emission | Manufacturing) distribution, obtained by summarizing the two subsidy cases.

Note that the slope is negative in each instance, because emissions decrease as supply increases. (The assumption of linearity, of course, implies that at some point the emission becomes negative; the linear model is reasonable only if the production size is limited to a narrow range.) The last panel in Figure 1 shows the $\mathrm{P}(\mathrm{c} \mid \mathrm{h})$ distribution, averaging over the two possible subsidy values and the two possible subsidy values. 

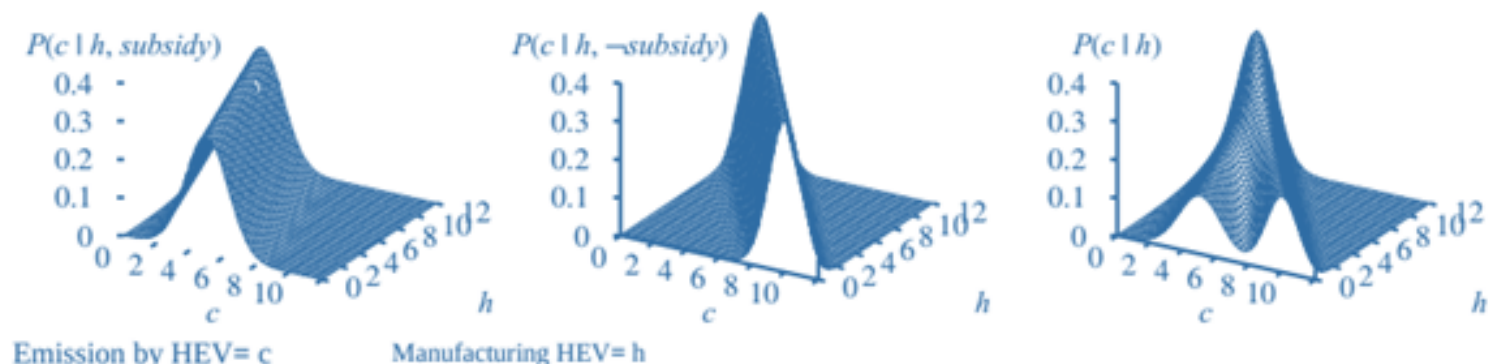

Emission by $\mathrm{HEV}=\mathrm{c}$

Figure 2 the distribution OF variables in network

We now discuss the distributions with continuous parents for discrete variables. The " Environmental quality " node in Figure 1., for instance, It seems reasonable to assume that the quality of the environment will increase if the emissions are low and decrease if they are high. The conditional distribution, in other words, is like a "soft" threshold function. The use of the Integral is one way to create soft thresholds

$$
\Phi(x)=\int_{-\infty}^{x} N(0,1)(x) d x
$$

Then the probability of "Environmental quality" given Emission is:

$$
\begin{gathered}
P(\text { Environmental quality } \mid \text { Emission }=c) \\
=\Phi\left(\frac{-c+\mu}{\sigma}\right)
\end{gathered}
$$


This means that the emission threshold is around $\mu$, the width of the threshold region is proportional to $\sigma$, and as emissions decrease, the probability of the environment increases.

\section{References}

[1] F. Che Jamil and A. Shariff Adli Aminuddin, "Preliminary study of Malaysian eco-friendly car selection by using analytic hierarchy process," in Journal of Physics: Conference Series, 2019.

[2] G. Rizzo, C. Pisanti, M. D'Agostino, and M. Naddeo, "Driver intention analysis for a throughthe-road solar hybridized car," in SAE Technical Papers, 2013.

[3] M. Tengiz, "NEW METHODOLOGYOF EVALUATING THE EFFICIENCYOF MANAGERIAL DECISION-MAKING," in Colloquium-journal, 2020, no. 8 (60).

[4] M. Tengiz, "APPLICATION OF GAME THEORYSIMULATION IN ENTERPRISE MANAGEMENT," in Colloquium-journal, 2020, no. 8 (60).

[5] T. Magradze, "MATHEMATICAL MO DELING IN THE ENTERPRISE MANAGEMENT," in Colloquium-journal, 2020, no. 7 (59).

[6] T. Magradze, "TAX ADMINISTRATION IN THE RUSSIAN FEDERATION: CURRENT PROBLEMS AND DEVELOPMENT PROSPECTS," in Colloquium-journal, 2020, no. 5 (57).

[7] R. Sanghvi and A. Gordon, "The plant-based-diet and obesity: The process and literature survey," 2021.

[8] L. James, "Impact of Digital Marketing on SME Growth in South Asia: A Case Study on Faheem Haydar Dealzmag."

[9] T. Choi, "Bayesian networks with examples in R," Biometrics, 2015.

[10] L. M. De Campos, J. M. Fernández-Luna, J. F. Huete, and M. A. Rueda-Morales, “Combining content-based and collaborative recommendations: A hybrid approach based on Bayesian networks," Int. J. Approx. Reason., 2010. 